\section{OS PROCESSOS HISTÓRICOS DE IMPLANTAÇÃO DA EDUCAÇÃO DO CAMPO NO MUNICÍPIO DE COLATINA - ES}

THE HISTORICAL PROCESS OF THE IMPLANTATION OF RURAL EDUCATION AT THE MUNICIPLE OF COLATINA - ES

\section{LOS PROCESOS HISTÓRICOS DE IMPLEMENTACIÓN DE CAMPO EDUCACIÓN EN EL MUNICIPIO DE COLATINA - ES}

Resumo: Este artigo traz uma breve socialização dos processos históricos de implantação da educação do campo no município de Colatina - ES, rememorando os principais marcos deste movimento em território camponês. Tem como objetivo apresentar a organização e atuação dos movimentos sociais comunitários, em vista da garantia de uma educação do campo. A metodologia baseou-se num estudo qualitativo. A principal estratégia utilizada na abordagem da pesquisa foi o estudo de caso. As técnicas adotadas na coleta de dados foram as entrevistas e a pesquisa documental acerca da temática investigada. Os resultados revelaram a insatisfação das famílias residentes na região de São João Pequeno e nas comunidades camponesas dos Vales de Boa Esperança e Santa Joana, observando seus filhos estudarem em escolas distantes e com realidades divergentes do contexto camponês. Essas constatações foram vivenciadas por muitos estudantes, familiares e camponeses de todo o Brasil, contribuindo com a organicidade dos movimentos sociais na luta, reivindicação e garantia de políticas públicas de educação do campo nos territórios camponeses. Evidenciamos nos resultados obtidos com a pesquisa bibliográfica, documental e de campo, a importância dessas organizações sociais no fortalecimento da educação do campo, enquanto modalidade da educação básica, até consolidar-se como direito da população camponesa. Nessa conjuntura, é cada vez mais necessário, semear e colher os frutos conquistados pelos movimentos organizados no chão das escolas do campo, na formação crítica e emancipadora dos educadores, familiares e comunidade escolar.

Palavras-chave: Movimentos Sociais. Políticas Públicas. Educação do Campo.

Recebido em: 10/02/2021

Alterações recebidas em: 24/05/2021

Aceito em: 25/05/2021

Publicação em: 09/06/2021
Ramofly Bicalho

Doutor em Educação

Professor na Universidade Federal Rural do Rio de Janeiro, Brasil.

E-mail:ramofly@gmail.com

Orcid: https://orcid.org/0000-0000-00000000

Gizele Kelfer

Mestre em Educação

Professora da Secretaria Municipal de

Educação de Colatina, Brasil

E-mail: gizele.kelfer@hotmail.com

Orcid: https://orcid.org/0000-0000-0000$\underline{0000}$

\section{Como citar este artigo:}

BICALHO, R.; KELFER, G. OS PROCESSOS HISTÓRICOS DE IMPLANTAÇÃO DA EDUCAÇÃO DO CAMPO NO MUNICÍPIO DE COLATINA - ES. Revista Espaço do Currículo, v. 14, n. 2, p. 1-16. 2021. ISSN 19831579. DOI:

https://doi.org/10.22478/ufpb.1983$1579.2021 \mathrm{v} 14 \mathrm{n} 2.57608$. 
Abstract: This article brings a brief socialization of the historical processes of implantation of the rural education in the city of Colatina - ES, recalling the main milestones of this movement in peasant territory. It aims to present the organization and performance of community social movements, with a view to ensuring rural education. The methodology was based on a qualitative study. The case study was the strategy used to approach the collection of data and information about the theme investigated. The results revealed the dissatisfaction of families residing in the region of São João Pequeno and in the peasant communities of the Vales de Boa Esperança and Santa Joana, observing their children studying in distant schools and with divergent realities from the peasant context. These findings were experienced by many students, families and peasants from all over Brazil, contributing to the organicity of social movements in the struggle, claim and guarantee of public policies for rural education in peasant territories. In the results obtained with bibliographic, documentary and field research, we have highlighted the importance of these social organizations in strengthening rural education, as a modality of basic education, until it is consolidated as the right of the peasant population. In this context, it is increasingly necessary to sow and reap the fruits conquered by movements organized on the ground of rural schools, in the critical and emancipatory formation of educators, family members and the school community.

Keywords: Social Movements. Public Politics. Rural Education.

Resumem: Este artículo brinda una breve socialización de los procesos históricos de implementación de la educación rural en el municipio de Colatina - ES, recordando los principales hitos de este movimiento en territorio campesino. Su objetivo es dar a conocer la organización y desempeño de los movimientos sociales comunitarios, con miras a garantizar la educación rural. La metodología se basó en un estudio cualitativo. La principal estrategia utilizada en el enfoque de investigación fue el estudio de caso. Las técnicas adoptadas en la recolección de datos fueron entrevistas e investigación documental sobre el tema investigado. Los resultados revelaron el descontento de las familias residentes en la región de São João Pequeno y en las comunidades campesinas de los Valles de Boa Esperança y Santa Joana, observando a sus hijos estudiar en escuelas distantes y con realidades diferentes del contexto campesino. Estos hallazgos fueron vividos por muchos estudiantes, familiares y campesinos de todo Brasil, contribuyendo a la organicidad de los movimientos sociales en la lucha, demanda y garantía de políticas públicas de educación rural en territorios campesinos. Evidenciamos en los resultados obtenidos con la investigación bibliográfica, documental y de campo, la importancia de estas organizaciones sociales en el fortalecimiento de la educación rural, como modalidad de educación básica, hasta consolidarse como un derecho de la población campesina. En esta coyuntura, se hace cada vez más necesario sembrar y cosechar los frutos conquistados por los movimientos organizados en el terreno de las escuelas rurales, en la formación crítica y emancipadora de educadores, familiares y comunidad escolar.

Palavras-clave: Movimientos sociales. Políticas públicas. Educación del campo.

\section{INTRODUÇÃO}

A intencionalidade deste texto nasceu da necessidade de refletir sobre a atuação dos movimentos sociais, na efetivação de políticas públicas específicas, que garantam o pleno acesso da população campesina aos direitos sociais, especialmente, uma proposta de educação que abrace, inclua e prepare para a vida. O objeto deste estudo tem como foco a comunidade camponesa de São João Pequeno e as demais localizadas nos Vales de Boa Esperança e Santa Joana, município de Colatina - ES.

Pesquisar sobre os sujeitos, seus contextos de vida e militância nestas comunidades, significa compreender a ameaça de extinção do conhecimento secular acumulado por gerações. Tais questões afetam diretamente a identidade camponesa dos estudantes que saem da comunidade para concluir seus estudos. Essas indagações foram se somando, dentre outros fatores, a educação básica interrompida na escola localizada na comunidade e sua possível continuidade na cidade. Com isso, as práticas culturais e o modo de vida dos camponeses, difundidos por meio da relação entre família e a proposta pedagógica curricular da escola, infelizmente, são invisibilizadas nos espaços escolares.

Este texto destina-se ainda, socializar os processos históricos de implantação da educação do campo no município de Colatina - ES, bem como a atuação dos movimentos sociais comunitários na 
trajetória de luta e resistência desses sujeitos que se organizam coletivamente, em prol de uma escola do campo no território onde residem e trabalham. Que aprendizagens os coletivos organizados dessa comunidade obtiveram? Que valores são atribuídos pela população local às escolas que enaltecem a história de luta dos camponeses e sua existência? À primeira vista, a instauração de uma escola na comunidade, com as características acima descritas, saciasse, de certa forma, as inquietações mais urgentes da população local. Para Arroyo (1999, p. 23): "A escola trabalha com sujeitos de direitos, a escola reconhece direitos, ou a escola nega direitos?". De que forma a escola nega direitos? Como a escola torna-se ponte entre os sonhos e a realidade? A educação é mantenedora de direitos quando se compromete com a formação de sujeitos politicamente conscientes. Segundo Arroyo (1999, p. 30):

Ter a concepção de que existem conhecimentos que são próprios do campo, [...] é ir às raízes culturais do campo e trabalhá-las como uma herança coletiva que mobiliza e inspira lutas pela terra, pelos direitos, por um projeto democrático e também pede educação.

Referindo-se à organização das escolas do campo, Antunes; Almeida; Martins (2012, p. 05) questionam que: "O que significa organizar as escolas do campo de modo a respeitar os tempos humanos? Significaria começar por tentar entender como são vividas as especificidades dos campos". As autoras idealizam processos educativos que exigem mudanças de valores e condutas sociais. Elas projetam transformações a serviço dos sujeitos sociais vinculados aos setores populares do campo, interagindo com as lutas sociais e a produção do conhecimento, numa perspectiva emancipatória de formação, articulada aos processos de superação da fragmentação do conhecimento. A proposta pedagógica curricular da escola do campo deve contemplar a especificidade do território camponês, considerando a complexidade das relações econômicas, sociais e políticas que os sujeitos camponeses estão inseridos.

O estudo de caso foi a estratégia utilizada na abordagem da coleta de dados acerca da temática investigada. Os procedimentos metodológicos aplicados para construção deste texto partiram das referências bibliográficas, análise documental, entrevistas e questionários.

$\mathrm{Na}$ pesquisa documental os materiais analisados foram os registros de atas de reuniões com educadores e famílias camponesas para implantação da Pedagogia da Alternância nas escolas do campo do município de Colatina, documentos referentes à Proposta Curricular e Organização Curricular das escolas do campo, PDI - Plano de Desenvolvimento Institucional, decretos e portarias municipais, imagens, vídeos, ou seja, documentos e arquivos públicos e particulares referentes à temática pesquisada que foram encontrados na unidade escolar, nas residências de algumas famílias, educadores e coordenadores (pedagógico e administrativo) e na Secretaria Municipal de Educação.

Para o desenvolvimento da entrevista, levou-se em consideração os sujeitos que participaram desde o início dessa luta que iniciou-se no ano de 2000, por meio do Projeto de Desenvolvimento Local Sustentável, organizado e articulado pela diretoria do Sindicato dos Trabalhadores Rurais de Colatina ES (Quadriênio 2001/2005). Sendo assim, o primeiro grupo entrevistado foram os membros dessa diretoria efetiva; o segundo foram os membros das Associações de Pequenos Agricultores das comunidades da abrangência da pesquisa; o terceiro foram os Educadores que participaram deste movimento e o quarto foram os jovens e adultos que tiveram que estudar em escolas localizadas na cidade e nos distritos, ou seja, distantes de sua comunidade. A seleção desses grupos de pessoas se baseou nas vivências, na atuação destes sujeitos e por eles serem os protagonistas da história, bem como no desenvolvimento do objeto pesquisado.

As principais referências teóricas que embasaram as reflexões sobre políticas públicas de educação do campo, movimentos sociais e pedagogia da alternância, foram: Antunes - Rocha (20120, Arroyo (1999 e 2007), Santos (2017 e 2019), Fernandes (1999 e 2004), Moschem (2020), Sindicato dos Trabalhadores Rurais de Colatina (2002), Martins (2008) e Zanotelli (2015). A seleção dos entrevistados considerou o protagonismo, atuação crítica e emancipadora dos sujeitos na educação do campo.

Os resultados dessa abordagem constataram que as famílias camponesas conhecem as escolas do 
campo vinculadas à proposta metodológica da pedagogia da alternância, reconhecidamente importante no atendimento às peculiaridades de tais sujeitos e na formação pedagógica, política, social e humana da comunidade escolar. Nessa conjuntura, inicia-se um movimento organizado por lideranças e famílias camponesas, nos Vales de Boa Esperança e Santa Joana, em vistas a implantação da educação do campo no município de Colatina.

\section{OS PRIMEIROS SINAIS}

O município de Colatina está localizado na região noroeste do estado do Espírito Santo. Conforme projeção do último censo do ano de 2010 para o ano de 2020, a população foi estimada em, aproximadamente, 123.400 pessoas. Atualmente, $88 \%$ da população está localizada na área urbana e $12 \%$ na área rural. Na década de 1990, a oferta da educação básica nas comunidades camponesas do município de Colatina correspondia somente até a quarta série do Ensino Fundamental. Para as séries finais dessa etapa e do Ensino Médio, o poder público disponibilizava o transporte escolar para os estudantes até as escolas localizadas nos distritos e na cidade. Os familiares desses estudantes que desejassem a continuidade dos estudos, tinham a opção de colocá-los no transporte escolar ou deixá-los na casa de parentes e/ou amigos da família que residiam nos distritos e/ou na cidade.

Essa decisão era muito difícil e dolorosa de ser tomada, pois significava o rompimento precoce de laços e vínculos familiares, bem como, a corresponsabilidade no cuidado entre os adolescentes e jovens, por ficarem longos períodos distante das famílias. Sem muitas opções, em virtude das inúmeras dificuldades apresentadas no campo, os familiares acabavam matriculando seus filhos em escolas distantes de suas casas, utilizando o transporte escolar, ou ainda, boa parte dos estudantes encerravam seus estudos na quarta série e seguiam trabalhando com os pais na roça. A utilização do transporte escolar, embora fosse uma oportunidade de continuidade dos estudos, geravam preocupações nos familiares, conforme esclarece a agricultora, militante e professora, (ZANOTELLI, 2015, p. 7-8):

Muitas vezes, o transporte escolar gratuito, oferecido pelo poder público, é a única forma de acesso à escola pelos moradores da área rural. Contudo, existem fatores que limitam e dificultam a prestação do serviço deste transporte, como, por exemplo, vias não pavimentadas, em péssimas condições de circulação, principalmente em período de chuva onde atoleiros e buracos se intensificam. [...] é comum veículos muito velhos e precários transportarem estudantes em área rural.

Os apontamentos de Zanotelli (2015) resultaram das insatisfações dos familiares com a prestação de serviço pelo poder público, por meio do transporte escolar. Elas tinham a preocupação de ficarem longe de seus filhos por um longo período, aproximadamente, 10 horas por dia. Com o uso frequente do transporte escolar, perceberam que o perigo maior, não era o tempo que seus filhos ficavam ausentes das famílias, mas sim, o percurso que faziam nas estradas, em péssimas condições, utilizando ônibus em situações precárias. A situação se agravava ainda mais, quando essas sucatas faziam o trajeto escolar no período das chuvas. Segundo Arroyo (2007, p. 3):

[...] os alunos são deslocados para as escolas urbanas, com professores urbanos e colegas urbanos. As crianças, adolescentes ou jovens do campo esqueceriam sua identidade e cultura para serem socializados junto à infância, adolescência e juventude urbanas, com identidade e cultura urbanas. Políticas que expressam o total desrespeito às raízes culturais, identitárias dos povos do campo.

O esquecimento da identidade e das raízes culturais dos estudantes camponeses, foi se evidenciando nas vivências com suas famílias. Não diria que seria apenas um esquecimento, mas negação da identidade camponesa, descaso e preconceito com a cultura de seus antepassados e familiares. Fruto do trabalho nas escolas urbanas que, ao desconhecerem as vivências e especificidades do território camponês, apresentam dificuldades em lidar com os estudantes do campo. Zanotelli (2015, p. 13) afirma: "que esse sistema afastava os filhos da roça e da família. $O$ ensino ofertado nessas escolas, além de resultarem na negação da identidade camponesa, fomenta o desinteresse de retorno para suas comunidades". Para Zanotelli (2015, p. 13): 
Em geral, aqueles que fazem o ensino médio em Colatina, não mais retornam para a roça, empregam-se na cidade e ali permanecem. Os moradores alegavam que o sistema de transporte escolar afastava os jovens da área rural, porque estes passavam a conviver com uma cultura mais urbana. Assim, os alunos aprendiam uma realidade fora da vivência familiar rural.

$\mathrm{Na}$ visão dos autores, a oferta do transporte escolar é o principal vilão para o deslocamento e permanência dos filhos dos agricultores na cidade. O reflexo disso se evidencia na escassez do jovem no campo, no interior do município de Colatina. Com o intenso êxodo rural, consequentemente, as comunidades vão se constituindo num público de perfil masculinizado e idoso. O jovem se distancia deste território. Ele não vislumbra mais o campo como lugar de vivência e formação humana. Uma visão, como diz Arroyo (2007, p. 2): "negativa do campo, como lugar do atraso e do tradicionalismo cultural". Conforme as informações contidas no Painel Representativo do Desenvolvimento Socioeconômico Cultural de Colatina - Panorama da educação do campo, INEP (2007, p. 37):

A oferta do transporte escolar tem sido objeto de um debate intenso, pois, enquanto os movimentos sociais e uma série de políticas governamentais buscam fixar o trabalhador rural no campo e assegurar a posse da terra para aqueles que a desejem cultivar, o transporte escolar atua em sentido inverso, levando o filho deste trabalhador para os núcleos urbanos.

Vale ressaltar que a utilização do transporte escolar e o processo educativo apresentado nas escolas distritais e da cidade não são os únicos fatores determinantes para o êxodo rural. Para Zago (2016, p. 18), pode-se: "considerar aspectos da realidade tanto micro, quanto macrossociais e uma análise que leve em conta as transformações sociais no campo e sua relação com a sociedade mais ampla". Os registros da autora chamam atenção para outros aspectos sociais do território camponês que desmotivam o jovem permanecer no campo. Esta é uma tarefa muito desafiadora e complexa. $O$ contexto de permanência do jovem no campo depende de políticas públicas no âmbito educacional, social, cultural e econômico (BICALHO, 2016).

\section{O INÍCIO DE UMA CAMINHADA}

Com o esvaziamento do público jovem no campo, as lideranças de algumas comunidades no interior do município de Colatina começaram a se preocupar, pois a situação se agravava e era comum às demais. Em meados da década de noventa, essas inquietações chegaram ao Sindicato dos Trabalhadores Rurais, como afirma Zanotelli (2015, p. 11 e 12):

De 1996 a 2002, fiz parte da diretoria do Sindicato dos Trabalhadores Rurais de Colatina, onde foram realizadas várias discussões sobre a melhoria das condições de vida para o povo campesino. Uma das pautas principais era sobre o modelo de educação que vinha sendo aplicado no campo, um ensino desvinculado de nossa realidade, causando assim um crescente esvaziamento do campo. Um modelo de ensino que contribuía com o êxodo rural. No final da década de 1990, participei de uma manifestação em Brasília, onde uma das principais reivindicações era a melhoria na educação do campo.

Nos registros acima, é perceptível a origem do êxodo rural atrelada ao modelo de ensino aplicado no campo, não somente no município de Colatina, mas a nível nacional. Nesse sentido, o desejo por melhorias na educação do campo é urgente, compondo um dos principais pontos de pauta nas diversas discussões da época. No memorial da educadora e militante Ana Paula Moschen, constam algumas informações importantes sobre esse contexto histórico:

Ao mesmo tempo em que se dá um grande êxodo das populações camponesas expropriadas de suas terras pelo avanço do projeto econômico / político / ideológico, ocorre, simultaneamente uma organização camponesa em nosso Estado articulado pelas organizações sindicais e religiosas, com destaque as CEBs - Comunidades Eclesiais de Base. Devido a esse processo há uma 
articulação regional de resistência de agricultores que vão ao encontro com os princípios da Pedagogia da Alternância trazidos por padres italianos para o ES, a partir da experiência das maison familiales rurales. Em Colatina, especificamente nas regiões Vale de Santa Joana (Comunidades de Santa Joana e São João da Barra Seca) e Vale da Boa Esperança (Distrito de Ângelo Frechiani), por volta da década de noventa, jovens camponeses, articulados pelas CEBs, discutem sobre a possibilidade de trazer a experiência da Pedagogia da Alternância para Colatina (MOSCHEN, 2020, p. 9).

As Comunidades Eclesiais de Base (CEBs), ligadas, principalmente, à Igreja Católica, estão organizadas por aproximação territorial entre moradores de uma determinada região e objetivos em comum, especialmente, os relacionados à falta de políticas públicas (BICALHO, 2016). A articulação com os movimentos sociais, Sindicato de Trabalhadores Rurais e grupos jovens oriundos da Igreja Católica, proporcionaram as primeiras discussões sobre a possibilidade de pensar uma proposta de educação que incluísse os sujeitos, individuais e coletivos, do campo, em diálogo com a pedagogia da alternância. No dia 17 de maio de 2020 realizamos uma entrevista com o educador e agricultor Edmilson Noventa, uma das principais lideranças residente no Vale de Boa Esperança. O entrevistado informou que:

Nestes encontros, discutia-se vários temas que, futuramente, traria melhorias para as comunidades, como por exemplo, meio ambiente, preservação das águas/nascentes, desmatamento, agroecologia, saúde, laser e outros. Porém, a que mais se discutia e que trazia indignação ao grupo era sobre o êxodo rural. As discussões nas comunidades eram organizadas em parcerias com a APTA Associação de Projetos em Tecnologias Alternativas, as CEBs e o Sindicato dos Trabalhadores Rurais de Colatina, onde originou-se o Projeto de Desenvolvimento Local Sustentável dos Vales de Boa Esperança e Santa Joana. Para início desses trabalhos, foram feitos diagnósticos nas comunidades com uma abordagem em diversos temas que propiciasse melhorias na qualidade de vida no campo. Nos diagnósticos o tema que mais se destacou foi em relação ao modelo de educação ofertado as crianças e adolescentes do campo, sendo que, o desejo de todos os moradores das comunidades pertencentes aos dois vales era que fossem atendidos com uma proposta de educação própria e apropriada, no e do campo.

Esse cenário de organização social, apresentado por Noventa, Moschem (2020) e Zanotelli (2015), revela os primeiros sinais do processo histórico da educação do campo no município de Colatina. Vale ressaltar que a Igreja Católica por meio das CEB's, teve contribuição importantíssima na vida da juventude que fazia parte das comunidades camponesas na década de 1990. Conforme os registros de Frei Betto (1985, p. 9):

É na zona rural que as comunidades de base mais proliferam. O homem do campo - pequeno-agricultor, boia fria, assalariado - encontra na Igreja seu principal referencial ideológico. Ao contrário do operário urbano, sua cultura está impregnada de religiosidade [...]. No caso brasileiro, os camponeses, desprovidos de apoio oficial, sem condições de obter crédito bancário, vítimas dos intermediários que pagam pouco pelo produto que depois revendem caro, não têm como se defender senão através do sindicato rural e das comunidades de base.

Frei Betto evidencia que os povos do campo encontravam nas igrejas e nos sindicatos rurais o apoio necessário para reivindicação dos direitos negados, especialmente, as injustiças causadas pelos atravessadores e intermediários que lucravam às custas dos camponeses, o descumprimento das leis trabalhistas em relação aos boias frias e a ausência histórica de políticas públicas. Tais situações, consequência da falta de apoio do poder público, ainda estão presente nas comunidades camponesas.

Conforme sinalizado, a Igreja Católica era uma das possibilidades de organização social que as 
famílias se apegavam, proporcionando momentos de reflexões críticas sobre o contexto vivido pelos sujeitos, individuais e coletivos, do campo. As CEB's, em parceria com o Sindicato dos Trabalhadores Rurais, encarregavam-se de levar os jovens agricultores a identificarem os temas relacionados à realidade vivida por eles, desenvolvendo um olhar crítico por meio da interpretação do mundo e a busca de melhorias para as comunidades.

No final da década de noventa, esses encontros foram se intensificando no Vale de Santa Joana, formado pelas comunidades: Córrego Estrela, São Brás, Boa Esperança, Santa Joana, São João da Barra Seca, Piabas I, Piabas II, São Luís da Barra Seca e no Vale de Boa Esperança, constituído pelas comunidades de Belo Aurora, Timbuí, Santa Rita, João Pretinho, São Lázaro, São Roque, Matedi e Graciano Neves. Dessa parceria floresceu o Projeto de Desenvolvimento Local Sustentável dos Vales de Santa Joana e Boa Esperança, Município de Colatina. Para retratar esse momento, Zanotelli (2015, p. 12) tem como referência, o Sindicato dos Trabalhadores Rurais de Colatina - ES:

Em 1999, a partir de fóruns de formação, capacitação, discussões, formulações, tomadas de decisões e execuções dos rumos e caminhos a serem seguidos, visando melhorar as condições de vida da população rural, surge o Projeto de Desenvolvimento Local Sustentável dos Vales do Santa Joana e de Boa Esperança no Município de Colatina, uma iniciativa dos agricultores e agricultoras dessas localidades, coordenado pelo Sindicato dos Trabalhadores Rurais. O projeto focalizava-se na elevação do nível de qualidade de vida e de cidadania da população dos vales, preferencialmente através de melhorias no contexto educacional da região. Visava uma maior inserção da categoria no conselho municipal de educação, buscando a reversão do então atual modelo para uma educação divergente, adaptando-a à realidade rural de forma acessível em todos os níveis (infantil, fundamental, médio e superior), que mesclasse os vários tipos de conhecimentos, abordando temas relativos à agroecologia, meio ambiente e outros inerentes ao cotidiano da população local, possibilitando aos jovens e adultos oportunidades diferenciadas de alfabetização regular, inserindo no processo educacional ações relativas à profissionalização da mão de obra, promovendo assim a elevação de nível de cidadania do conjunto das pessoas envolvidas no projeto.

O Projeto de Desenvolvimento Local Sustentável dos Vales de Santa Joana e de Boa Esperança oficializou as propostas, sonhos e desafios que nasciam no chão dessas comunidades, com foco na garantia de políticas públicas no campo, especialmente, aquelas que se referiam ao contexto educacional vivenciado nas diversas etapas da educação básica.

Uma das primeiras ações do projeto foi fazer um diagnóstico nas comunidades, considerando, predominantemente, os aspectos de cunho social e cultural, para se ter um panorama da realidade local. Segundo o Projeto de Desenvolvimento Rural Sustentável, do Sindicato dos Trabalhadores Rurais de Colatina - ES (2002, p. 63): "a educação é o fator preponderante que permeia todas as ações do Projeto como uma política fomentadora das transformações sociais desejadas pela população". Conforme o cenário diagnosticado, o modelo de educação adotado nas escolas das comunidades, nos distritos e na cidade, tinha uma visão estritamente urbana com dificuldades para desenvolver atividades que atendessem as expectativas dos estudantes do campo e seus familiares.

Com as fragilidades e ameaças à identidade camponesa apresentadas no diagnóstico, o passo seguinte do Projeto foi a organização e mobilização das comunidades locais na conquista de escolas distritais de Ensino Fundamental, no modelo de educação agroecológica das Escolas Famílias Agrícolas. A proposta do Projeto definiu que o processo educativo atenderia as especificidades das famílias camponesas, dialogando com a realidade local, as injustiças, os sonhos, festas e desafios presente na vida daquelas pessoas. O próximo passo dado pelas lideranças dos Vales de Santa de Joana e Boa Esperança, seria levar tais propostas ao conhecimento do poder público, embora sem apoio do governo municipal. 


\section{A TRAJETÓRIA DE LUTA POR UMA EDUCAÇÃO DO CAMPO}

Os anos se passaram e o sonho pela escola continuava vivo para os moradores dos Vales de Santa Joana e Boa Esperança. Segundo Moschem (2020, p. 9):

Uma década depois, o então prefeito possibilita às comunidades um debate acerca da educação. Quando se reúnem nos vales supracitados, o tema sobre Pedagogia da Alternância ressurge com muita força. O processo de implantação de uma Escola com essa nova metodologia começa a ser discutida dentro da Secretaria. Com dificuldades estruturais e financeiras, surge a possibilidade de implantar a escola dentro do terreno da Escola Agrotécnica Federal - hoje IFES Campus Itapina.

O debate a que se refere Moschem (2020) acerca da educação nas comunidades, deu-se por meio da elaboração do Plano Municipal de Educação, iniciado por volta de 2002. Nessas discussões, as famílias e os jovens não perderam a oportunidade de mais uma vez, reivindicarem uma escola pautada na metodologia da Pedagogia da Alternância (PA), pois esta, é considerada a proposta metodológica mais apropriada a ser desenvolvida em território camponês:

Os dados levantados nos livretos, em relação à educação rural, reforçam essa política. Os representantes das comunidades campesinas que participaram das assembleias regionais e das conferências municipais de educação enfatizaram, em suas manifestações, a necessidade de implantação de um projeto educativo que leve em conta as características da vida daquelas comunidades. [...] No entanto, é urgente a elaboração de uma política que permita a construção de uma prática educativa a partir das necessidades identificadas pela população campesina, através de seus representantes a chamada Pedagogia da Alternância, que se consolidou como uma prática voltada para a realidade rural, tem sido o tema de seminários e reuniões com lideranças comunitárias, que estão sendo realizados com o objetivo de implantar uma unidade escolar no início de 2004: a Escola Municipal de Ensino Fundamental Agroecológica. Essa escola funcionará em área cedida pela Escola Agrotécnica Federal e atenderá prioritariamente crianças e adolescentes da região de Itapina, aproximadamente a um total de 22 comunidades (SEMED/PME, 2004, p. 20).

O diálogo mais próximo com o poder público permitiu debates na Secretaria Municipal de Educação sobre o processo de implantação da escola com essa metodologia. Porém, conforme pontuou Moschem (2020), devido as dificuldades estruturais e financeiras enfrentadas pelo município, a escola poderia ser implantada no terreno do IFES, Campus Itapina, e não nas comunidades dos Vales. A partir de 2004, nasce a Escola Municipal de Ensino Fundamental (EMEF) "Agroecológica", atendendo os estudantes de São João Pequeno e São Pedro Frio, tendo como referência metodológica a PA. Segundo Zanotelli (2015, p. 14):

O sonho de uma escola rural na comunidade teve que mais uma vez ser adiado. O projeto da Escola Família Agrícola, ou Escola Agroecológica foi sim aprovado e concretizado, mas não na localidade onde foi idealizado. Por interferências maiores, foi remanejado para outra localidade, e em vez de atender às necessidades daqueles que o conceberam, originalmente seu público-alvo, que tomou a iniciativa de fomentá-lo, o projeto acabou sendo instaurado na EMEF Agroecológica, em Itapina.

Marta Elena Zanotelli é moradora da comunidade de São João da Barra Seca, pertencente a Região do Vale de Santa Joana. Ela participou ativamente das primeiras discussões sobre a necessidade de ter nas regiões dos dois Vales, escolas pautadas na PA. Em seus registros, evidencia-se um sentimento de revolta pelo fato da escola por eles idealizada, ter sido remanejada para outra localidade. Não que a outra região não merecesse, mas pela falta de consideração por toda luta e inúmeras solicitações realizadas pelas famílias do Vale de Santa Joana. A EMEF "Agroecológica" teve um tempo curto de existência, 
encerrando-se suas atividades no final do ano letivo de 2010 e os estudantes remanejados para outras escolas do município. No dia 26 de maio de 2020, Ana Carla Loss Furlan1, Coordenadora Administrativa no período de encerramento das atividades, fez o seguinte relato acerca do que vivenciou na escola:

No decorrer do desenvolvimento das atividades na EMEF "Agroecológica”, foram surgindo algumas situações desafiadoras que estavam comprometendo a realização da proposta da PA, bem como, o funcionamento da Escola de modo geral. Como por exemplo, alguns dos educadores não tinham e desconheciam a identidade camponesa, não alimentavam o sentimento de pertença por aquela Escola, nem pela proposta e não se identificavam com a metodologia, mesmo havendo formação continuada que Ihes davam embasamento teórico e prático para realização de um trabalho com qualidade. Outro fator agravante era o fato de a Escola ter sido implantada em uma localidade distante das comunidades em que os estudantes moravam. Isso dificultou muito o diálogo e a parceria com as famílias. Além dos estudantes continuarem percorrendo caminhos longos e ficarem um bom tempo dentro do transporte escolar, eles e seus familiares, não tinham aquele sentimento de pertença pela Escola, por mais que eles cuidavam dela e lutavam para que ela continuasse existindo, a Escola estava muito distante deles, das comunidades. Acredito que, isso foi um dos fatores que mais dificultou a permanência do funcionamento da EMEF "Agroecológica".

O depoimento de Furlan sinaliza que uma escola do campo deve colaborar no processo de ensino e aprendizagem, oportunizando a interação com os estudantes, familiares e comunidade. Além disso, deve ser território de organização social para as lideranças. Apesar das divergências ocorridas na escola, a Secretaria Municipal de Educação investiu na PA, prestando assessoria pedagógica e administrativa, em diálogo com a equipe escolar, estudantes e familiares. Inúmeros registros, atas e encaminhamentos foram realizados. No entanto, os estudantes não tinham ânimo de ir à escola, achavam o percurso muito cansativo e as famílias sem motivação de estar presente na escola. Diante dessas situações, no final do ano letivo de 2010, encerraram-se as atividades e o atendimento na EMEF "Agroecológica".

No que se refere ao perfil do educador/a do campo, mesmo que não seja da comunidade e desconheça a realidade camponesa, é fundamental que se aproprie desses elementos, atendendo às especificidades da escola. Para Arroyo (2007) o conhecimento das formas específicas de exercer o ofício de educar no campo ultrapassa o ensino focado apenas nos conteúdos dos componentes curriculares.

O educador que escolhe trabalhar nessas escolas precisa, segundo Arroyo (2007, p. 167): "conhecer a centralidade da terra e do território na produção da vida, da cultura, das identidades, da tradição e dos conhecimentos". Precisa se despir dos hábitos da escola e da cultura urbana e se apropriar das singularidades existentes no território camponês e nas escolas do campo. Para Furlan, é estratégica a formação específica dos educadores do campo, pautada na integração das áreas do conhecimento e numa concepção transdisciplinar de produção emancipadora do conhecimento. Ainda em Arroyo (2007, p. 169):

Os movimentos sociais têm clareza de que a conformação do sistema de educação com uma rede de escolas do campo no campo e com um corpo profissional com formação específica exige educadoras e educadores do campo no campo. Sabemos que um dos determinantes da precariedade da educação do campo é a ausência de um corpo de profissionais que vivam junto às comunidades rurais, que sejam oriundos dessas comunidades, que tenham como herança a cultura e os saberes da diversidade de formas de vida no campo. A maioria das educadoras e educadores vai, cada dia, da cidade à escola rural e de lá volta a seu lugar, a cidade, a sua cultura urbana. Consequentemente, nem

\footnotetext{
1 Professora dos anos iniciais do Ensino Fundamental da Escola Unidocente Municipal (EUM) "São Salvador". Atualmente compõe a equipe de formação do Setor de Educação do Campo, Secretaria Municipal de Educação de Colatina. Participou ativamente do movimento de implantação da educação do campo no município de Colatina.
} 
tem suas raízes na cultura do campo, nem cria raízes.

A precariedade da educação do campo conceituada por Arroyo (2007) é o que mais compromete a qualidade do ensino nas escolas no campo. Não diria que o educador, necessariamente, deveria morar na comunidade onde a escola está inserida. Porém, é fundamental que se aproprie da proposta curricular, do contexto histórico, social e cultural da comunidade, participando dos debates e formação acerca das políticas públicas de educação do campo, na interface com os movimentos sociais (BICALHO, 2017). Educadores/as que não se identificam e nem manifestam interesse em atender às especificidades da escola e familiares, põe em risco todo esforço dos movimentos sociais organizados e da comunidade escolar na continuidade da escola do campo. Segundo Gava (2011, p. 80):

O fato da Escola estar localizada em uma área distante das comunidades onde os estudantes viviam era um elemento que dificultava enormemente a participação das famílias e o seu envolvimento no processo educativo. A essência da Pedagogia da Alternância estava sendo posta em suspenso. Sem diálogos frequentes com as famílias e comunidades a Escola ficou isolada em um espaço que passou a ser apenas escolar, sem interatividades com a realidade e os sujeitos camponeses.

A essência da PA é a efetiva participação das famílias na gestão compartilhada da escola e no processo de ensino e aprendizagem dos estudantes. Essas ações, contribuem para participação dos familiares na escola, desperta o sentimento de pertença e faz sentido na vida das pessoas. Nessa conjuntura, cuidam, lutam e defendem a escola do campo na comunidade. Realizam mutirões, reformas, hortas, comemorações, faxinas, entre tantos outros eventos, em diálogo aberto com toda comunidade escolar.

Mesmo com os desafios e as fragilidades apresentadas na EMEF "Agroecológica", o sonho por esse modelo de escola e metodologia continuava existindo nas famílias das comunidades no interior de Colatina. Esse desejo manifestava-se nos vários espaços que os agricultores se faziam presentes, conforme reunião realizada na Escola Municipal Comunitária Rural (EMCOR) Padre Fulgêncio do Menino Jesus:

Em novembro de 2009, um novo planejamento é realizado pelo poder público, através do PPA - Plano Plurianual. A reunião aconteceu na Escola Municipal de Ensino Fundamental Padre Fulgêncio do Menino Jesus, na comunidade da Reta Grande, Distrito de Ângelo Frechiani, com as famílias de toda a região, inclusive as do Vale da Boa Esperança. Os mesmos jovens que sonharam por essa escola estavam presentes, mas agora em condição de pais e mães. E mais uma vez reivindicaram com muito vigor por uma escola própria e apropriada para seus filhos [...]. (PDI - EMCOR “PADRE FULGÊNCIO DO MENINO JESUS”, 2017-2021, p. $46-47)$.

As famílias insistiam numa escola que atendesse os estudantes de suas comunidades. Não queriam reviver com seus filhos o que eles viveram, ou seja, andar por mais de uma hora no transporte escolar, conceber o campo como lugar do atraso e receber uma educação rural desvinculada da realidade camponesa. Interessante destacar que em relação à educação rural, o Plano Municipal de Educação (2004 - 2013, p. 69), no que se refere as Diretrizes Municipais e Metas Prioritárias, considera:

Implantar escolas voltadas para a realidade rural, com a metodologia da alternância, a partir de discussões com as comunidades interessadas, para o $2^{\circ}$ segmento do ensino fundamental; Promover uma maior integração entre a comunidade e a escola, que vise a atender as especificidades de cada comunidade, enquanto desenvolve uma visão cada vez mais abrangente da relação cidade-campo; Atualizar e/ou enriquecer o currículo da $1^{\mathrm{a}}$ fase da educação fundamental inovando a sua base conceitual e reorientando seus conteúdos e práticas. 
Tendo como referência as prioridades estabelecidas no Plano Municipal de Educação, fortalecidas no solo das comunidades camponesas, fomentou-se o desejo de uma escola do campo próxima da comunidade. Em novembro 2009, na Escola Municipal de Ensino Fundamental "Padre Fulgêncio do Menino Jesus", em reunião com a presença do Prefeito Leonardo Deptulski, representantes do poder público e familiares da região, foi discutido o planejamento, as normativas e estratégias de desenvolvimento das ações para os anos seguintes, por meio do Plano Plurianual (PPA). Os camponeses reivindicavam uma escola do campo que dialogasse com sua realidade e os reconhecessem como sujeitos históricos e culturais. Para atender à solicitação das famílias, seria necessário substituir a proposta de ensino regular da escola pela perspectiva metodológica da PA. Em entrevista, Noventa relata que:

Em 2010, o Prefeito Leonardo abriu discussão sobre a mudança da proposta metodológica da Escola Municipal de Ensino Fundamental "Padre Fulgêncio do Menino Jesus". Foi quando a representante da Secretaria Municipal de Educação, Ana Paula Moschen, juntamente com as lideranças daquela região, iniciaram um trabalho intenso de reuniões nas comunidades, com o objetivo de apresentar a proposta metodológica da PA e orientá-los quanto as mudanças que viriam.

Conforme mencionado anteriormente, os estudantes da região de São João Pequeno estudavam na EMEF "Agroecológica". Como a escola ficava muito distante de suas residências, muitos deles paravam de estudar, além dos familiares não conseguirem participar ativamente das atividades e demandas que Ihes competiam. Diante desses desafios, as lideranças das comunidades se manifestaram quanto ao desejo de uma escola mais próxima de onde residem. No final do ano de 2009 as famílias dos estudantes, moradores e educadores das escolas multisseriadas das comunidades de abrangência da Região de São João Pequeno, ficaram motivadas e esperançosas que a solicitação fosse concedida. Nesse sentido, iniciam-se as articulações na comunidade:

A comunidade discutia o risco de vida que corriam os alunos por irem estudar longe de casa. Saíam de manhã e, quando chovia, chegavam em casa até às 10 horas da noite. A inclusão da Pedagogia da Alternância [na comunidade] foi com muita luta. Somamos esforços: pais e monitores, vieram para dentro da comunidade formaram comissões para buscar solução na Secretaria Municipal de Educação. Foram mais ou menos 2 anos nesse processo. (Nivaldo Monteiro relatando o movimento pela reabertura de uma escola que havia sido fechada na comunidade de São João Pequeno) (RACEFFAES, 2015, p. 38).

O depoimento de Nivaldo representa o testemunho das famílias dos estudantes daquela região em relação a preocupação, desespero e lamentação das pessoas expostas aos riscos das estradas intransitáveis e outras dificuldades. Tais sentimentos reverteram-se em coragem na luta pela reabertura da escola na comunidade. Conforme os registros no documento do Plano de Desenvolvimento Institucional (PDI) da EMCOR "São João Pequeno" (2017-2021), consta a informação de que, desde o ano de 2007 , os educadores das escolas multisseriadas identificaram a importância da oferta dos anos finais do Ensino Fundamental:

Entretanto, a partir de 2007 os educadores das escolas multisseriadas desta região iniciaram uma formação pela Secretaria Municipal de Educação a partir do Projeto Construindo e Reconstruindo a Educação Rural - CRER, e tiveram a oportunidade de refletir a realidade da região onde estavam inseridos. A partir destas discussões constataram que a região necessitava de oferecer a formação também para as séries finais a seus estudantes para garantir o direito ao acesso e permanência de todos na escola, já que o número de estudantes que paravam de estudar devido à distância do percurso era suficiente para garantir as turmas (PDI - EMCOR “SÃO JOÃO PEQUENO”, 2017-2021, p. 50).

Na região, existiu o atendimento aos anos finais do Ensino Fundamental, conforme registrado no PDI da EMCOR "São João Pequeno" (2017 - 2021, p. 51): “A expansão para o ginásio ocorreu no ano de 
1974, com 26 alunos. Em 1985, por motivo não relatado foram encerradas as atividades das séries finais da escola, causando tristeza e revolta da população, que nada pode fazer para mudar esta situação". Nesses registros, percebe-se que o atendimento foi por um período curto de, aproximadamente, onze anos. A tristeza e a revolta adormecida ressurgem com muita força após algumas décadas.

Moschen orienta os educadores/as a fazerem o levantamento do número de estudantes que concluiriam o quinto ano dos anos iniciais do Ensino Fundamental, nas escolas multisseriadas de abrangência da Região de São João Pequeno, no final do ano letivo de 2010. Foerste \& Gava (2013, p. 262), retratam, exatamente, o momento em que o referido levantamento foi apresentado ao Poder Público:

O levantamento foi levado ao Prefeito de Colatina, que acionou a equipe da SEMED, por intermédio da Secretária de Educação. A partir de então, foram feitos estudos sobre quantos estudantes saíam daquela localidade para estudar em outras escolas, em outras comunidades. Muitos andavam mais de $50 \mathrm{~km}$ dentro do ônibus do transporte escolar para chegar até à escola, todos os dias, indo para a Escola Distrital, em Itapina, ou para a "Agroecológica".

A partir de então, sob as orientações da equipe da SEMED, iniciou-se um trabalho intenso, porém gratificante, nas comunidades. Assim relatou Schmild: ${ }^{2}$

Depois que eu tinha em mãos o número de estudantes certo para comprovar que tinha estudantes na região, foram feitas as reuniões em todas as comunidades perguntando se eles queriam a metodologia da PA na escola em São João Pequeno. Todas as famílias concordaram e assinaram as atas que eram feitas nas reuniões. Depois em dezembro do ano de 2010, eu passei em todas as escolas multisseriadas para fazer as matrículas, e onde não tinha a escola, eu marcava um local com as famílias para fazer as matrículas. No final do ano, eu e os professores das multisseriadas, organizamos um evento onde o prefeito veio anunciar a reabertura da escola para todos da região de São João Pequeno. Nós arrumamos e enfeitamos tudo, ficou a coisa mais linda! Muita gente compareceu.

Com a aceitação das famílias e o apoio do poder público, começaram-se as articulações comunitária e política com vista a organização das atividades e, em atendimento as solicitações realizadas pelas lideranças do Vale de Boa Esperança e a Região de São João Pequeno. Essas foram as primeiras ações realizadas por meio da Secretaria Municipal de Educação, com investimentos de cunho administrativo, pedagógico e nos espaços físicos das escolas, além de incentivar a formação dos educadores na perspectiva da PA.

Em 2011, o ano letivo inicia com a implementação da proposta metodológica da PA na Escola Municipal de Ensino Fundamental "Padre Fulgêncio do Menino Jesus" e o processo de transferência da EMEF "Agroecológica" para Região de São João Pequeno, na Escola Pluridocente Municipal (EPM) "São João Pequeno". De acordo com a Lei n 5.734, de 29 de junho de 2011, onde alterou-se a denominação da Escola Municipal de Ensino Fundamental "Padre Fulgêncio do Menino Jesus" para Escola Municipal Comunitária Rural (EMCOR) "Padre Fulgêncio do Menino Jesus". A Lei n 5.735, de 29 de junho de 2011, por sua vez, alterou a denominação da Escola Pluridocente Municipal "São João Pequeno" para Escola Municipal Comunitária Rural (EMCOR) "São João Pequeno".

Em 2011, com o movimento de expansão da PA nas escolas da Região de São João Pequeno e do Distrito de Ângelo Frechiani, as famílias manifestaram preocupação sobre a continuidade dos estudos de seus filhos na alternância, quando da conclusão do Ensino Fundamental e ingresso no Ensino Médio, provavelmente, nas escolas convencionais. Na tentativa de alcançarem o objetivo coletivo, essas famílias procuraram o Conselho Municipal de Educação de Colatina/ES e apresentaram suas preocupações. A

\footnotetext{
${ }^{2}$ Fátima Adagmar Jadjeski Fialho Schmild - Professora da EUM Cabeceira de Monte Belo, moradora da região de São João Pequeno, participou ativamente dos primeiros movimentos comunitários em busca de uma Educação do e no Campo, na região.
} 
orientação foi que procurassem a Secretaria Estadual de Educação e apresentassem a proposta coletiva de continuidade da PA, a fim de autorizarem a criação da escola de Ensino Médio. De acordo com os registros da ata de reunião do Comitê de Educação do Campo do Município de Colatina, realizada no dia 11 de junho de 2015, na EMCOR “Padre Fulgêncio do Menino Jesus", retomou-se o caminho percorrido pelas famílias em busca de seus objetivos.

Diante dessa solicitação a Secretaria Estadual de Educação e a Superintendência Regional de Educação de Colatina, em visita à região, e em conjunto com a comunidade escolar, organizaram todos os requisitos necessários para que a Escola Estadual Comunitária Rural iniciasse as atividades letivas no ano de 2012 oferendo a Educação Profissional Técnica Integrada ao Ensino Médio - Técnico em Agropecuária com os princípios da Pedagogia da Alternância (SEMED, 2015).

Em 2012, inicia-se o atendimento aos estudantes do Ensino Médio, na Escola Estadual Comunitária Rural de Colatina, com a oferta do $1^{\circ}$ ano. Em 2013, o $2^{\circ}$ ano e assim, sucessivamente. A escola funcionou no mesmo espaço físico da EMCOR "Padre Fulgêncio do Menino Jesus", em função das articulações e parcerias estabelecidas entre os servidores da rede municipal e estadual. Segundo Zanotelli (2015, p. 14):

No ano de 2013, após um período de inércia, as comunidades do Vale de Santa Joana voltaram a se organizar, com o apoio do Conselho Municipal de Educação, em torno de um projeto de escola comunitária, aos moldes da pedagogia da alternância, para atender aos estudantes das etapas posteriores do ensino já oferecido nas comunidades da região.

A aprovação do projeto de escola comunitária aos moldes da PA, no Vale de Santa Joana, foi concedida em 2015 para início das atividades no ano de 2016, após muitas tentativas e insistências das lideranças das comunidades. A trajetória de luta dessas famílias em busca da educação do campo, esteve a todo momento vinculada à organicidade dos movimentos sociais da Região do Vale de Santa Joana. Destacamos ainda, como marco importantíssimo na educação do campo em Colatina, a implantação da Lei Municipal $n^{\circ} 6.362$, de 03 de novembro de 2016, que regulamentou a Lei Municipal $n^{\circ} 5.864$, de 10 de julho de 2012. No Art. $1^{\circ}, \S 1^{\circ}$ :

A oferta da Educação do Campo será realizada de acordo com os princípios da metodologia da Pedagogia da Alternância do sistema CEFFA - Centros Familiares de Formação em Alternância, conforme o Parecer CNE/CEB nº 01/2006 e será promovida por criação e/ou adaptação pedagógica de escolas para o atendimento da Educação Infantil e Ensino Fundamental e terá descrição própria e específica na Resolução do Conselho Municipal de Educação, no Plano Municipal de Educação, no Regimento Comum das Escolas Municipais Comunitárias Rurais, no Regimento Comum das Escolas Unidocentes e Pluridocentes Comunitárias e no Regimento Comum das Escolas Municipais de Colatina.

A aprovação dessa lei contribuiu na garantia de efetivação dos princípios metodológicos da PA na Escola Unidocente Municipal (EUM) "São Salvador", Escola Pluridocente Municipal (EPM) "São João Pequeno" e Escola Municipal Comunitária Rural (EMCOR's) Padre Fulgêncio do Menino Jesus, bem como, a valorização das especificidades da modalidade de educação do campo, através dos documentos e legislações publicadas pelo município de Colatina, com a participação do Comitê de Educação do Campo, Conselhos, Associações de Escolas, educadores, lideranças das comunidades camponesas e Poder Legislativo. Vale pontuar que o Plano Municipal de Educação (PME) (2004 - 2013), sinalizou para necessidade de implantação da metodologia da PA nos anos finais do Ensino Fundamental. O PME (2015 - 2025), defende a garantia dessas especificidades, não apenas nos anos finais, mas em todas as etapas de ensino ofertadas nas EUM's, EPM's e EMCOR's.

As estratégias descritas no referido texto do PME (2015 - 2025) garante o desenvolvimento da proposta metodológica da PA nas escolas do campo, especialmente, a formação continuada dos 
educadores, calendário, organização curricular e proposta pedagógica específica que atenda às políticas públicas de educação do campo. O plano defende a manutenção das escolas, considerando o território camponês em sua totalidade, evitando o fechamento e a nucleação das mesmas, além da utilização do transporte escolar intracampo. Diante de tais colocações, ao menos teoricamente, é evidente o crescimento das políticas públicas de educação do campo no município de Colatina.

Infelizmente o sonho realizado durou pouco tempo. Devido inúmeros fatores demandados do poder público, especificamente, da rede estadual, a Escola Estadual Comunitária Rural de Colatina foi impossibilitada de ofertar o Ensino Médio, encerrando suas atividades no final do ano letivo de 2018. Mesmo com esse retrocesso na educação do campo em Colatina, as famílias da região continuaram se mobilizando para reverter tal situação.

\section{CONSIDERAÇÕES FINAIS}

Compreendemos que todas as lutas e organização comunitária das lideranças tinham como principal objetivo garantir uma proposta pedagógica que atendesse as especificidades da identidade camponesa, bem como, a oferta do direito à educação no território onde residem e trabalham. Empoderados deste movimento de luta, as famílias da comunidade de São João Pequeno, dos Vales de Santa Joana e Boa Esperança, insistem numa proposta de educação do campo, em diálogo com suas histórias de vida, angústias e a realidade de modo geral. Para Arroyo \& Fernandes (1999, p. 6):

[...] A educação escolar ultrapassa a fase "rural", da educação escolar "no" campo e passa a ser "do" campo [...]. Vai-se, portanto, além da "escolinha de letras" (ler, escrever, contar) para se trabalhar participativa e criativamente um projeto de Brasil, um projeto de Campo, resgatando e valorizando os valores culturais típicos do povo do campo.

As famílias ansiavam por uma proposta de trabalho que reconhecesse, refletisse e valorizasse o contexto histórico, social, econômico e cultural dos sujeitos, individuais e coletivos, do campo. As Diretrizes Operacionais para a Educação Básica nas Escolas do Campo (BRASIL, 2001) enfatizam que o campo é: "mais do que um perímetro não-urbano, é um campo de possibilidades que dinamizam a ligação dos seres humanos com a própria produção das condições da existência social e com as realizações da sociedade humana". Os sujeitos camponeses, diante desse cenário de militância e organização social, resistem na luta por políticas públicas de educação do campo.

Nas entrevistas com os familiares dos jovens das escolas localizadas nos distritos e na cidade, o elemento que desencadeou todo processo de organização social no final da década de 1990, foi a insatisfação acerca da escolarização dos seus filhos, perda de identidade cultural com o distanciamento da comunidade de origem, condições de acesso à escola e, consequentemente, o seu retorno para casa. Esses sujeitos coletivos relataram o desejo por uma escola do campo articulada aos movimentos sociais na garantia dos seus direitos e vinculada às especificidades da realidade camponesa.

Evidenciamos a organicidade dos familiares, as lutas em prol de políticas públicas de educação do campo e o desejo que seus filhos estudassem numa escola que respeitasse às especificidades das comunidades camponesas. Segundo Fernandes (2012 p. 17): “Esta luta é uma semeadura. Plantamos nos campos dos desafios as esperanças e as resistências". E foi com a esperança da semente germinar e colher os frutos, que as famílias, coletivamente organizadas, não desistiram de semear e sonhar com a conquista dos seus objetivos. Segundo Antunes Rocha; Martins (2012, p. 27):

A presença dos Movimentos Sociais como sujeitos coletivos na Educação do Campo amplia as possibilidades de entendimento do que podemos chamar de processo formativo, articulado à construção de outra organização societária. $\mathrm{O}$ espaço/tempo da luta, da conquista, da construção de vínculos solidários e do trabalho cooperativo colocam a alternância não somente como afirmação do que está dado, mas como processo capaz de gerar novas alteridades, novas culturas e novas sociedades, provocando alterações nos sujeitos e na cultura, vivenciado como um processo coletivo. 
O processo formativo vivenciado pelos sujeitos que constituem os movimentos sociais, está baseado na construção do trabalho cooperativo e na vivência dos espaços comunitários nos territórios camponeses. A trajetória de luta na implantação da educação do campo é oriunda dos sujeitos coletivos. Percebemos nos resultados dessa pesquisa, que a pedagogia da alternância gerou novas possibilidades para as comunidades camponesas, contribuindo na consolidação dos movimentos sociais camponeses. Esperamos que este texto contribua nas reflexões, problematizações e encaminhamentos que estão por vir, na esperança de fortalecer os movimentos sociais na garantia de políticas públicas de educação do campo, que faça sentido na vida dos camponeses.

\section{REFERÊNCIAS}

ANTUNES ROCHA, Maria Isabel; ALMEIDA MARTINS, Maria de Fátima; ALVES MARTINS, Aracy. Territórios Educativos na Educação do Campo: Escola, Comunidade e Movimentos Sociais. 2. ed. Belo Horizonte: Gutenberg, 2012.

ARROYO, Miguel Gonzalez. Políticas de formação de educadores (as) do campo. Caderno Cedes, Campinas, v. 27, n. 72, p. 157-176, maio/ago. 2007. Disponível em: http://www.cedes.unicamp.br. Acesso em: 13 jun. 2020.

ARROYO, Miguel Gonzalez. Prefácio. In: KOLLING, Edgar Jorge (Org.). Por uma educação básica do campo. Brasília: Fundação Universidade de Brasília, 1999.

BETTO, Frei. O que é Comunidade Eclesial de Base. São Paulo: Brasiliense, 1985.

BICALHO, Ramofly. Possíveis Interfaces entre Educação do Campo, Educação Popular e Questões Agrárias. Curitiba: Appris, 2017. v. 1.234 p.

BICALHO, Ramofly; SILVA, M. A. Políticas públicas em educação do campo: PRONERA, PROCAMPO e PRONACAMPO. Revista Eletrônica de Educação, São Carlos, v. 10, n. 2, p. 135-144, 2016.

COMITÊ DE EDUCAÇÃO DO CAMPO DO MUNICÍPIO DE COLATINA. Regimento Interno. Colatina, 2012. p. $5-6$.

ESCOLA MUNICIPAL COMUNITÁRIA RURAL “PADRE FULGÊNCIO DO MENINO JESUS”. Plano de Desenvolvimento Institucional. Colatina, 2017-2021.

ESCOLA MUNICIPAL COMUNITÁRIA RURAL “SÃO JOÃO PEQUENO”. Plano de Desenvolvimento Institucional. Colatina, 2017-2021.

FERNANDES, Bernardo Mançano; ARROYO, Miguel Gonzalez. A educação básica e o movimento social do campo. Coleção Por uma Educação Básica do Campo, Brasília, v. 2, 1999.

FOERSTE, Erineu; GAVA, Marleide Pimentel Miranda. Educação do Campo: Diálogos Interculturais em “Terras Capixabas". Vitória: Edufes, 2013. p. 262.

GAVA, Marleide Pimentel Miranda. Professores do campo e no campo: um estudo sobre a formação continuada e em serviço na Escola Distrital "Padre Fulgêncio do Menino Jesus", no município de Colatina/ ES. Vitória: UFES, 2011.

INSTITUTO NACIONAL DE ESTUDOS E PESQUISAS EDUCACIONAIS ANÍSIO TEIXEIRA. Painel Representativo do Desenvolvimento Socioeconômico Cultural de Colatina. Panorama da educação do campo. Brasília: INEP, 2007.

MOSCHEN, Ana Paula. Memorial acadêmico de uma professora dos anos iniciais de uma escola multisseriada do campo: a diversidade de tempos, idades e saberes das crianças do campo. São Mateus - ES, 2020.

REGIONAL DAS ASSOCIAÇÕES DOS CENTROS FAMILIARES DE FORMAÇÃO EM ALTERNÂNCIA DO ESPÍRITO SANTO. Cultivando a Educação dos Povos do Campo do Espírito Santo. São Gabriel da Palha, 2015. p. 29.

SECRETARIA MUNICIPAL DE EDUCAÇÃO. Ata da reunião do Comitê de Educação do Campo do 
Município de Colatina. Colatina, 2015.

SECRETARIA MUNICIPAL DE EDUCAÇÃO. Plano Municipal de Educação: Bases Político - Pedagógicas da Educação Municipal- por uma escola participativa 2004 - 2013. Colatina, 2004.

SECRETARIA MUNICIPAL DE EDUCAÇÃO. Plano Municipal de Educação de Colatina: 2015 - 2025. Colatina, 2015.

SINDICATO DOS TRABALHADORES RURAIS DE COLATINA - ES. Projeto de Desenvolvimento Local Sustentável: Vales de Boa Esperança e Santa Joana. 1. ed. Colatina: Gráfica Tidabel, 2002. p. 41/63.

ZAGO, Nadir. Migração rural-urbana, juventude e ensino superior: Universidade Comunitária da Região de Chapecó. Revista Brasileira de Educação, Chapecó, v. 21 n. 64, p. 18/19, jan/mar. 2016.

ZANOTELLI, Marta Elena. Caminhos da Educação do Campo: Um olhar sobre a Comunidade de São João da Barra Seca- Curso de Pedagogia da Alternância. Colatina: Secretaria Municipal de Educação, 2015.

Este obra está licenciado com uma Licença Creative Commons Atribuição-NãoComercial 4.0 Internacional. 